\title{
Air- and Dust-Borne Fungi in Indoor and Outdoor Home of Allergic Patients in a Dust-Storm-Affected Area
}

\author{
Elham Shabankarehfard, Afshin Ostovar, Shokrollah Farrokhi, Behrouz \\ Naeimi, Sasan Zaeri, Shahrokh Nazmara, Mozhgan Keshtkar, Farzaneh \\ Sadeghzadeh \& Sina Dobaradaran
}

To cite this article: Elham Shabankarehfard, Afshin Ostovar, Shokrollah Farrokhi, Behrouz Naeimi, Sasan Zaeri, Shahrokh Nazmara, Mozhgan Keshtkar, Farzaneh Sadeghzadeh \& Sina Dobaradaran (2017): Air- and Dust-Borne Fungi in Indoor and Outdoor Home of Allergic Patients in a DustStorm-Affected Area, Immunological Investigations, DOI: 10.1080/08820139.2017.1322102

To link to this article: http://dx.doi.org/10.1080/08820139.2017.1322102

Published online: 25 Jul 2017.

Submit your article to this journal $\llbracket$

View related articles $\nearrow$

View Crossmark data $\nearrow$ 


\title{
Air- and Dust-Borne Fungi in Indoor and Outdoor Home of Allergic Patients in a Dust-Storm-Affected Area
}

\author{
Elham Shabankarehfarda, Afshin Ostovarb, Shokrollah Farrokhic, Behrouz Naeimi ${ }^{\mathrm{d}}$, \\ Sasan Zaerie, Shahrokh Nazmaraf ${ }^{\mathrm{f}}$, Mozhgan Keshtkara ${ }^{\mathrm{a}}$, Farzaneh Sadeghzadeh" ${ }^{\mathrm{g}}$, \\ and Sina Dobaradaran ${ }^{a, h, i}$
}

\begin{abstract}
aDepartment of Environmental Health Engineering, Faculty of Health, Bushehr University of Medical Sciences, Bushehr, Iran; ${ }^{b}$ Department of Infectious Diseases, The Persian Gulf Tropical Medicine Research Center, The Persian Gulf Biomedical Sciences Research Institute, Bushehr University of Medical Sciences, Bushehr, Iran; 'Department of Immunology, Asthma and Allergy, The Persian Gulf Tropical Medicine Research Center, The Persian Gulf Biomedical Sciences Research Institute, Bushehr University of Medical Sciences, Bushehr, Iran; ${ }^{d}$ Department of Microbiology and Parasitology, Faculty of Medicine, Bushehr University of Medical Sciences, Bushehr, Iran; 'Department of Pharmacology, Faculty of Medicine, Bushehr University of Medical Sciences, Bushehr, Iran; 'Department of Environmental Health Engineering, School of Public Health, Tehran University of Medical Sciences, Tehran, Iran; 'Department of Medical Laboratory Sciences, Faculty of Paramedical, Bushehr University of Medical Sciences,

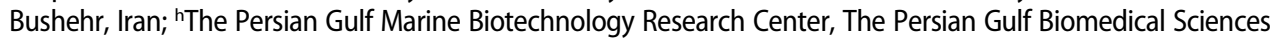
Research Institute, Bushehr University of Medical Sciences, Bushehr, Iran; 'Systems Environmental Health, Oil, Gas and Energy Research Center, The Persian Gulf Biomedical Sciences Research Institute, Bushehr University of Medical Sciences, Bushehr, Iran
\end{abstract}

\begin{abstract}
Despite the recent increases in fungi-induced allergic diseases, there is no report yet in the region of the Persian Gulf on concentration levels of fungi in relationship with health state. Therefore, our aim was to measure fungi prevalence as well as to evaluate the relationships between air- and dust-borne fungal genera and allergic diseases. A matched case-control study was carried out including 45 allergic cases and 45 age- and gendermatched controls for each individual. Indoor and outdoor dust and indoor air samples were collected from participant homes during May to October 2015. A Quick Take 30 Pump and sterile wet swab were used to determine fungal types and their amounts in the air $\left(\mathrm{CFU} / \mathrm{m}^{3}\right.$ ) and dust (CFU/100 $\mathrm{cm}^{2}$ ) samples, respectively. A significant reverse association was found between indoor dust-borne Alternaria and asthma (Odds ratio $(O R)=0.14$, $95 \% \mathrm{Cl}=0.02-0.86)$. Contrarily, increased levels of indoor airborne Aspegillus fumigatus $(\mathrm{OR}=2.00,95 \% \mathrm{Cl}=0.37-10.55)$ and Alternaria $(\mathrm{OR}=3.00,95 \% \mathrm{Cl}=0.34-25.83)$ were correlated with asthma development. Also, correlation analysis showed a significant relation between indoor air-borne Penicillium levels and reactivity to skin prick test in asthmatic patients $(p=0.04)$. Our findings support the notion that fungal exposures can either cause or prevent the development of allergic diseases. Accordingly, appropriate measures should be taken for a better management of fungi-induced allergic diseases.
\end{abstract}

\section{KEYWORDS}

Air-borne; allergic rhinitis; asthma; atopic dermatitis; dust-borne; fungi

CONTACT Sina Dobaradaran s.dobaradaran@bpums.ac.ir E The Persian Gulf Marine Biotechnology Research Center, Boostan 19 Alley, Imam Khomeini Street, Bushehr, Iran.

Color versions of one or more of the figures in the article can be found online at www.tandfonline.com/iimm. 


\section{Introduction}

Allergic diseases include life-threatening anaphylaxis, certain forms of asthma, food allergies, rhinitis, angioedema, conjunctivitis, urticaria, and eczema due to increased prevalence, as well as the morbidity and mortality have come to be recognized as a main worldwide public health problem (Hong et al., 2008; Pawankar et al., 2011; Khora, 2016). Allergic diseases affect different organs including upper and lower respiratory tract, eyes, skin, etc. (Crameri et al., 2014) through changing activity levels of the immune system (Mosca et al., 2015). The prevalence of these diseases has increased in the recent decades (Sánchez-Lerma et al., 2009). Exposure to indoor and outdoor allergens plays an important role in the development of such diseases (Bush et al., 2006; Sharma et al., 2011). Fungi are considered as major allergens with notable contribution to the etiology of allergic diseases. In this regard, indoor fungi have recently received more emphasis as most people spend more than $50 \%$ of their time at home and breathe about $10 \mathrm{~m}^{3}$ of indoor air daily (Adhikari et al., 2004; Sen \& Asan, 2009; Sharma et al., 2012). Some allergic diseases such as asthma, atopic dermatitis and allergic rhinitis are more linked with fungi (Sharma et al., 2012; Crameri et al., 2014). Hence, the quality of the inhaled indoor air in relation to the presence of fungal species is a crucial factor in the occurrence and progression of the mentioned diseases.

Some studies have been conducted to determine fungal prevalence in different areas; recent studies in the United States' revealed that predominant air-borne fungi in homes were Cladosporium, Penicillium, Aspergillus, Alternaria (Shelton et al., 2002; O'Connor et al., 2004; Crawford et al., 2015). In another study in Turkey, it was found that Penicillium (28.61\%), Cladosporium (16.08\%) and Alternaria (15.98\%) were the most prevalent air-borne fungi (Sen \& Asan, 2009). Moreover, an Iranian study reported Penicillium (39.5\%), Cladosporium (17.7\%), Yeast (18.7\%), and Aspergillus (13\%) as the most abundant air-borne fungi (Chadeganipour et al., 2010).

The amount of fungi in living environment depends on different factors including relative humidity, temperature and concentration level of outdoor fungi species (Bush \& Portnoy, 2001; Tang, 2009; Al-Barakah et al., 2014). Environmental and geographical characteristics of the living area such as direction and speed of winds are the other important factors that affect the amounts of fungi. In this respect, dust storms in some regions are considered effective in determining indoor and outdoor fungal levels. They are able to carry biological entities such as fungal spores up to several miles away from the original place (Kellogg \& Griffin, 2006; Chao et al., 2012). Since the last decade dusty storms have extensively emerged in the western and southwestern parts of Iran which affect many environmental and ecobiological habitats (Assarehzadegan et al., 2013; Akhzari et al., 2014; Amanollahi et al., 2015). Accordingly, it was reported that the prevalence of fungi increased during dust storm days in the mentioned regions with Cladosporium, Alternaria, Aspergillus, Penicillium and Rhizopus as the five dominant fungi genera (Soleimani et al., 2013). Bushehr Port is located in the southwestern Iran and northern part of the Persian Gulf with an area of $984.50 \mathrm{~km}^{2}$ and 195222 inhabitants. Bushehr has repeatedly encountered dusty storms in the recent years. It should be noted that the climate in Bushehr is hot and humid due to proximity to the Persian Gulf. Hence, this area potentially has the predisposing environmental conditions for the occurrence of allergic manifestations associated with air- and dust-borne fungal species. This hypothesis 
is supported by a recent study that showed a significant rise in the incidence of allergic diseases in Bushehr Port (Farrokhi et al., 2014; Gheybi et al., 2014).

To the best of our knowledge, there is no report yet in the region of Persian Gulf (which countries are located with large areas of desert) on concentration levels of fungi relationship with health state. Therefore, the objectives of the present study are (i) to determine the prevalence of different indoor and outdoor fungal genera present in the dust as well as indoor air samples and (ii) to evaluate the relationship between the concentration levels of different fungi and the health state (either healthy or atopic) of the participants. This study also evaluates the association, in terms of odds ratio, of the allergic diseases such as asthma, atopic dermatitis and allergic rhinitis with fungi concentration levels in the air and dust of participants' houses, as a first matched case-control study on mentioned topic in the region of the Persian Gulf. Findings of the present study would provide insights into preventative measures to control allergic diseases associated with fungal allergens.

\section{Method}

\section{Study design}

Skin prick test (SPT) was performed to determine the sensitivity of each individual to fungal allergen extracts. Fifteen patients with positive SPT reactions to extract of at least one fungal species (Aspergillus fumigatus, Penicillium nonatume and Alternaria alternate) were finally included in the study for each of the mentioned allergic subsets. The inclusion criteria were as follows: patients of $>1$ year age residing in Bushehr, Iran (at least for 1 last year), and with allergic symptoms at the time of sampling. The clinical classification/ diagnosis was performed in agreement to established definitions. AS was diagnosed according to the criteria of the global initiative for asthma (GINA) (http://ginasthma. org. Accessed 2017), AR following the recommendations of the Allergic Rhinitis and its Impact on Asthma (ARIA) consortium (http://www.whiar.org. Accessed 2017) and AD by the criteria defined in Guidelines of Care for the Management of Atopic Dermatitis (Eichenfield et al., 2014). For each individual patient, a best friend control with the same age ( \pm 3 years) and gender was selected. For each allergic patient younger than 12 , the appropriate control individual with similar age and lifestyle was selected. Location of the homes sampled in city is shown in Figure 1. All the patients and their respective matched controls participated in the study voluntarily after obtaining a verbal consent. All participants were treated in accordance with the guidelines of the Ethics Committee of Bushehr University of Medical Sciences.

\section{Skin prick test}

As mentioned above SPT was carried out on allergic patients with antigen extracts from fungal species including Aspergillus fumigatus, Penicillium nonatume and Alternaria alternate. SPT was performed in accordance with a standard method (Dreborg, 1989). Briefly, it was done as a single test on two forearms with lancets and standardized allergens. The patients were advised not to take antihistamines (for $72 \mathrm{~h}$ ) and other sympathomimetic drugs (for 8-12 h) before the test. A wheal diameter of $\geq 3 \mathrm{~mm}$ was considered as a positive 


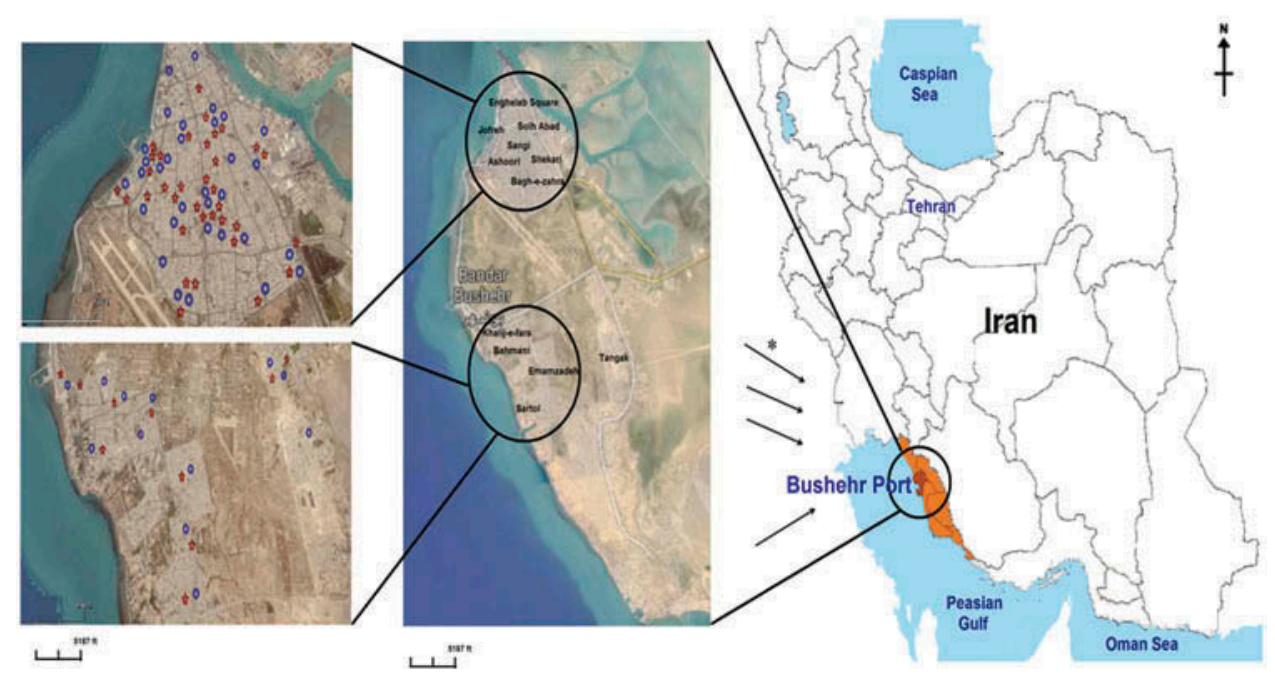

Figure 1. Map of Bushehr showing location of the homes sampled (star, homes of the patients; and circle, homes of the controls). ${ }^{*}$ ) Direction of dusty storms that usually pass the intended area throughout the year.

reaction. Histamine hydrochloride $(10 \mathrm{mg} / \mathrm{ml})$ and glycerin saline were used as positive and negative controls, respectively. SPT was reported for each patient either as mild (wheal diameter $=3-5 \mathrm{~mm}$ ) or moderate to severe (wheal diameter $\geq 5 \mathrm{~mm}$ ) following skin pricking of each of the following fungal extracts: Aspergillus, Alternaria and Penicillium.

\section{Sampling and laboratory methods}

Indoor and outdoor dust and indoor air sampling for both the case and control groups were done during May to October 2015. To determine fungal types and their amounts in the indoor air, the air of three main spaces including master bedroom, kitchen and living room which had the highest traffic of the habitants were sampled by using a portable Quick Take 30 Sample Pump (USA, SKC Corporation) with a single biostage. The biostage consisted of a plate containing Sabouraud 4\% Dextrose Agar media. Sampling was performed from the center part of the aforementioned spaces at a height of $1.5 \mathrm{~m}$ off the floor (i.e. in the breathing height of the residents) with a flow rate of $28.3 \mathrm{~L} / \mathrm{min}$ for 10 minutes. Prior to each sampling, isopropanol was used to disinfect the biostage of the pump. The results are presented as colony forming units per cubic meters $\left(\mathrm{CFU} / \mathrm{m}^{3}\right)$. These values were calculated as follows:

$$
\mathrm{CFU} / \mathrm{m}^{3}=\frac{\text { Number of fungal colonies }(\mathrm{CFU})}{\text { Timed sampled }(\mathrm{min})} \times \frac{1 \text { minute }}{\text { Sampling rate }(\mathrm{L})} \times \frac{1000 \mathrm{~L}}{1 \mathrm{~m}^{3}}
$$

Dust samples were collected from the horizontal surfaces of the aforementioned places and also outside the door where most commonly used to enter the building. For this purpose, a sterile swab wetted with normal saline was used in an area of $100 \mathrm{~cm}^{2}$. Immediately, samples were cultured in the Sabouraud 4\% Dextrose Agar media under a sterile condition. The results are presented as $\mathrm{CFU} / 100 \mathrm{~cm}^{2}$. 
The media plates were incubated at $27^{\circ} \mathrm{C}$ for 5-8 days and fungal colonies on each plate were identified and counted on a daily base. Identification of fungi was done mainly at the level of genera using either slide culture technique or high power microscopy.

Several other variables such as age, gender, temperature, relative humidity, wind velocity and sunny hours of day were also recorded. Relative humidity and temperature of sampled homes were measured (by using PHB-318, Lotrun, Taiwan) during the sampling time.

\section{Statistical analysis}

Demographic and environmental variables were described using frequencies and percentages for categorical variables and mean and standard deviation for continuous variables among cases and controls. Frequencies and percentages of various fungi in indoor and outdoor dust as well as indoor air were compared between cases and control. Odds ratio and its respective 95\% confidence interval was calculated using McNemar test for matched case-control studies to evaluate the association of fungal genera in indoor/outdoor samples and atopies (Asthma, Atopic Dermatitis and Allergic Rhinitis).

\section{Results}

Forty five patients with the diagnosis of asthma (AS) $(N=15)$, atopic dermatitis (AD) $(N=15)$ and allergic rhinitis (AR) $(N=15)$ who referred to the allergy clinic of teaching hospital of Bushehr, Iran, were enrolled in the study through a convenience sampling. Patients with asthma, atopic dermatitis and allergic rhinitis $(N=45)$ were individually matched with healthy controls without any allergic symptoms $(N=45)$ and similar lifestyles as well as conditions in order to compensate for the unknown confounding factors. The mean values of age and gender percentiles of cases and controls are shown in Table 1. With respect to age, a range of 2-64-year-old subjects participated in the study with statistical analysis revealing no significant difference between cases and their matched controls $(P>0.05)$. A total of 64 female and 26 male subjects participated in the study. Also, the environmental and weather conditions of sampling places are presented in Table 1. The indoor and outdoor temperatures were found to vary from 25.7 to $27.2^{\circ} \mathrm{C}$ and 27.95 to $28.9^{\circ} \mathrm{C}$, respectively. The indoor and outdoor relative humidity ranged from 47.57 to $52.06 \%$ and from 59.77 to $78.94 \%$, respectively. The maximum and minimum velocities of wind on the sampling days showed a difference of $10.2 \%$. Also, the sunny hours per day ranged between 9.31 to 10.22 hours during the study period. It should be noted that statistical analysis of the above mentioned parameters did not show any significant differences between case and control groups (data not shown) A total of 18 different fungal genera and six Aspergillus species were recognized in the present study (Table 2). The most prevalent fungal genera cultured from indoor dust were Yeast (86.6\%), Aspergillus (A. niger 9\% and A. flavus 1.48\%), and Alternaria (1.07\%). Outdoor dust samples consisted of Yeast (60\%), Alternaria (26\%), and Aspergillus (A. niger 8.4\% and A. flavus 2.9\%) as the most prevalent genera. Yeast (46.38\%), A. niger $(25.21 \%)$, Penicillium (6.8\%), and A. flavus (5.25\%) were found to be predominant genera in the indoor air samples. Generally, cultured fungi showed similar diversities among indoor air, indoor, and outdoor dust samples. However, some genera were found only in one specific 


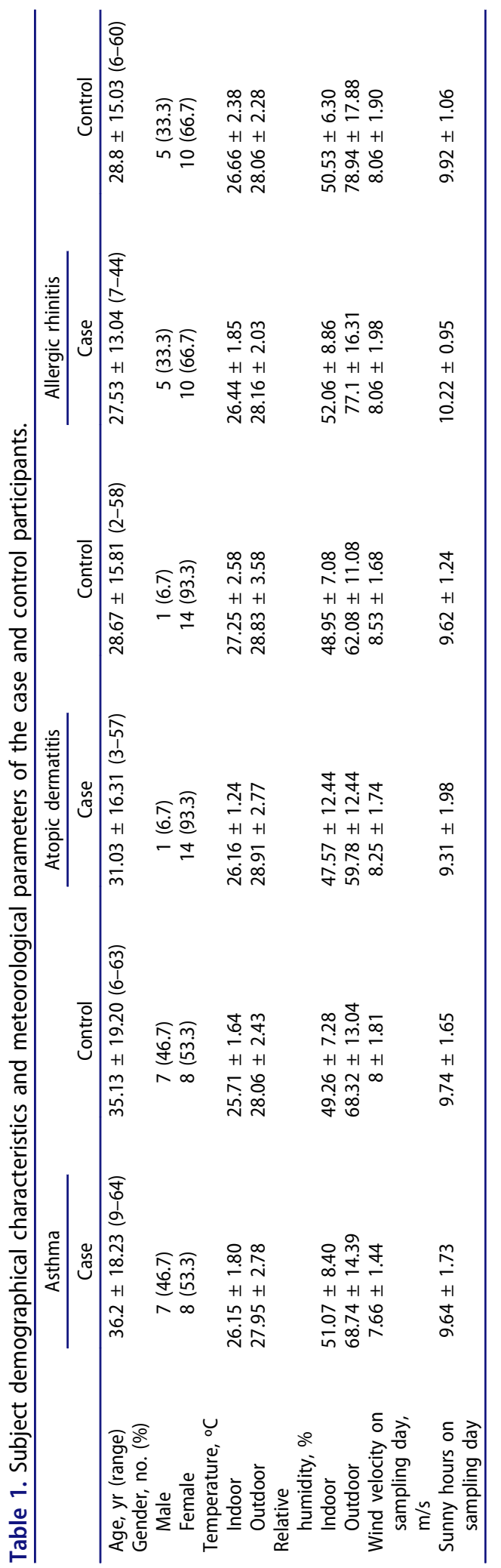


Table 2. The most abundant fungi types (\%) in indoor/outdoor dust and air samples.

\begin{tabular}{|c|c|c|c|c|c|}
\hline \multirow{2}{*}{$\begin{array}{l}\text { Indoor dust } \\
\text { Fungi }\end{array}$} & \multirow[b]{2}{*}{ Prevalence (\%) } & \multicolumn{2}{|c|}{ Outdoor dust } & \multicolumn{2}{|c|}{ Indoor air } \\
\hline & & Fungi & Prevalence (\%) & Fungi & Prevalence (\%) \\
\hline Yeast $^{*}$ & (86.619) & Yeast* & (60) & Yeast* & $(46.38)$ \\
\hline Aspergillus niger & (9) & Alternaria & (26) & Aspergillus niger & $(25.21)$ \\
\hline Aspergillus flavus & (1.48) & Aspergillus niger & (8.4) & Penicillium & $(6.801)$ \\
\hline Alternaria & $(1.07)$ & Aspergillus flavus & $(2.9)$ & Aspergillus flavus & $(5.258)$ \\
\hline Rhizopus & $(0.65)$ & Penicillium & $(0.94)$ & Alternaria & $(4.842)$ \\
\hline Penicillium & $(0.41)$ & Rhizopus & $(0.91)$ & Aspergillus terreus & (3.115) \\
\hline Cladosporium & $(0.2)$ & Mucor & $(0.5)$ & Mucor & $(2.72)$ \\
\hline Mucor & $(0.17)$ & Aspergillus fumigatus & $(0.2)$ & Cladosporium & (1.682) \\
\hline Fusarium & $(0.12)$ & Aspergillus Sp. & $(0.2)$ & Rhizopus & $(1.626)$ \\
\hline Aspergillus terreus & $(0.06)$ & Cladosporium & $(0.09)$ & Aspergillus fumigatus & $(0.726)$ \\
\hline Aspergillus fumigatus & $(0.05)$ & Fusarium & $(0.087)$ & Crisosporium & $(0.591)$ \\
\hline Bipolaris & $(0.047)$ & Aspergillus terreus & (0.074) & Aspergillus restrictus & $(0.346)$ \\
\hline Phoma & $(0.033)$ & Aspergillus nidulance & $(0.07)$ & Acromonium & $(0.298)$ \\
\hline Paecilomyses & $(0.023)$ & Bipolaris & $(0.05)$ & Aspergillus Sp. & $(0.122)$ \\
\hline Sansefalestrum & $(0.021)$ & Phialophora & $(0.03)$ & Fusarium & $(0.071)$ \\
\hline Aspergillus nidulance & $(0.013)$ & Paecilomyses & $(0.02)$ & Scopolariupsis & $(0.063)$ \\
\hline Acromonium & $(0.009)$ & Acromonium & $(0.01)$ & Paecilomyses & $(0.047)$ \\
\hline Aspergillus Sp. & $(0.007)$ & & & Bipolaris & $(0.038)$ \\
\hline Aspergillus restrictus & $(0.006)$ & & & Phialophora & $(0.028)$ \\
\hline Phialophora & $(0.002)$ & & & Aspergillus nidulance & $(0.021)$ \\
\hline Crisosporium & $(0.002)$ & & & Sansefalestrum & $(0.01)$ \\
\hline Drechserella & $(0.00079)$ & & & Stymphilium & $(0.004)$ \\
\hline Curvularia & (0.00079) & & & Drechserella & $(0.004)$ \\
\hline
\end{tabular}

${ }^{*}$ Yeast refers to all types of yeast species isolated in this study.

Table 3. Percentage of homes (\%) that were contaminated with different fungi in case and control groups.

\begin{tabular}{|c|c|c|c|c|c|c|}
\hline \multirow[b]{2}{*}{ Fungi } & \multicolumn{2}{|c|}{$\begin{array}{l}\text { Homes (\%) with indoor dust- } \\
\text { borne fungus }\end{array}$} & \multicolumn{2}{|c|}{$\begin{array}{c}\text { Homes }(\%) \text { with outdoor dust- } \\
\text { borne fungus }\end{array}$} & \multicolumn{2}{|c|}{$\begin{array}{c}\text { Homes (\%) with indoor air- } \\
\text { borne fungus }\end{array}$} \\
\hline & Case & Control & Case & Control & Case & Control \\
\hline Yeast & 100 & 100 & 93.3 & 97.8 & 97.8 & 100.0 \\
\hline Aspergillus niger & 100 & 93.0 & 88.9 & 82.2 & 97.8 & 100.0 \\
\hline Aspergillus flavus & 86.7 & 64.4 & 71.1 & 55.6 & 88.9 & 82.2 \\
\hline Alternaria & 71.1 & 55.6 & 48.9 & 48.9 & 80.0 & 80.0 \\
\hline Rhizopus & 57.8 & 68.9 & 31.1 & 33.3 & 46.7 & 57.8 \\
\hline Penicillium & 40 & 35.6 & 26.7 & 35.6 & 55.6 & 57.8 \\
\hline Cladosporium & 28.9 & 22.2 & 8.9 & 11.1 & 33.3 & 33.3 \\
\hline Mucor & 20 & 11.1 & 11.1 & 8.9 & 8.9 & 13.3 \\
\hline Aspergillus fumigatus & 11.1 & 15.6 & 2.2 & 11.1 & 20.0 & 28.9 \\
\hline Aspergillus terreus & 11.1 & 11.1 & 11.1 & 2.2 & 24.4 & 11.1 \\
\hline Fusarium & 8.9 & 8.9 & 4.4 & 6.7 & 4.4 & 8.9 \\
\hline Aspergillus Sp. & 8.9 & 2.2 & 6.7 & 6.7 & 17.8 & 11.1 \\
\hline Bipolaris & 6.7 & 4.4 & 2.2 & 0.0 & 11.1 & 2.2 \\
\hline Aspergillus restrictus & 4.4 & 2.2 & 0.0 & 0.0 & 2.2 & 6.7 \\
\hline Aspergillus nidulance & 4.4 & 2.2 & 2.2 & 0.0 & 2.2 & 2.2 \\
\hline Paecilomyses & 2.2 & 6.7 & 2.2 & 2.2 & 6.7 & 4.4 \\
\hline Phialophora & 0.0 & 4.4 & 0.0 & 2.2 & 2.2 & 2.2 \\
\hline Stymphilium & 0.0 & 0.0 & 0.0 & 0.0 & 2.2 & 0.0 \\
\hline Acromonium & 2.2 & 2.2 & 2.2 & 0.0 & 0.0 & 4.4 \\
\hline Crisosporium & 0.0 & 4.4 & 0.0 & 0.0 & 0.0 & 8.9 \\
\hline Drechserella & 2.2 & 0.0 & 0.0 & 0.0 & 2.2 & 0.0 \\
\hline Scopolariupsis & 0.0 & 0.0 & 0.0 & 0.0 & 0.0 & 2.2 \\
\hline Sansefalestrum & 2.2 & 0.0 & 0.0 & 0.0 & 2.2 & 0.0 \\
\hline Curvularia & 2.2 & 0.0 & 0.0 & 0.0 & 0.0 & 0.0 \\
\hline Phoma & 0.0 & 2.2 & 0.0 & 0.0 & 0.0 & 0.0 \\
\hline
\end{tabular}


sample category mentioned above. For example, Phoma genus was found only in indoor dust samples while Stymphilium and Scopolariupsis genera were specific to indoor air samples. Furthermore, Crisosporium and Sansefalestrum were present only in indoor air and dust samples. Totally, the most and least prevalence among all fungal genera belonged to Yeast (65.5\%) and Curvularia (0.0008\%), respectively.

Distribution of case and control homes in terms of presence/absence of different air- and dust-borne fungi is shown in Table 3. Higher percentages of homes (either case or controls) were contaminated with yeast, Aspergillus niger, Aspergillus flavus, Alternaria, Rhizopus, Penicillium and Mocur.

Association between fungal genera and three cited allergic groups (asthma, atopic dermatitis, and allergic rhinitis) are shown in Table 4 in terms of odds ratios. A significant reverse association was found between indoor dust-borne Alternaria and asthma $(\mathrm{OR}=0.14,95 \% \mathrm{CI}$ $=0.02-0.86$ ). On the contrary, increased levels of indoor air-borne Aspegillus fumigatus $(\mathrm{OR}=2.00,95 \% \mathrm{CI}=0.37-10.55)$ as well as indoor air-borne Alternaria $(\mathrm{OR}=3.00,95 \%$ $\mathrm{CI}=0.34-25.83)$ were found to be suggestive risk factors for asthma development. Data analysis also revealed the positive associative trend between outdoor dust-borne Penicillium $(\mathrm{OR}=2.00,95 \% \mathrm{CI}=0.37-10.55)$ and development of atopic dermatitis. Moreover, indoor air-borne Aspegillus flavus ( $\mathrm{OR}=2.00,95 \% \mathrm{CI}=0.19-21.03)$, outdoor dust-borne Alternaria $(\mathrm{OR}=2.00,95 \% \mathrm{CI}=0.37-10.55)$, indoor dust-borne Cladosporium $(\mathrm{OR}=2.00,95 \%$ $\mathrm{CI}=0.37-10.55)$ and indoor air-borne Cladosporium $(\mathrm{OR}=3.00,95 \% \mathrm{CI}=0.34-25.83)$ all showed high odds ratios for the occurrence of allergic rhinitis.

Table 4. Association of fungal genera in indoor/outdoor samples with atopies (asthma, atopic dermatitis, and allergic rhinitis).

\begin{tabular}{|c|c|c|c|}
\hline \multirow[b]{2}{*}{ Fungal genera } & Asthma & Atopic dermatitis & Allergic rhinitis \\
\hline & OR $(95 \% \mathrm{Cl})$ & OR $(95 \% \mathrm{Cl})$ & OR $(95 \% \mathrm{Cl})$ \\
\hline \multicolumn{4}{|c|}{ Aspergillus flavus } \\
\hline Indoor dust ${ }^{1}$ & $0.33(0.07-1.52)$ & $0.25(0.03-1.89)$ & $0.00(0.00)$ \\
\hline Outdoor dust ${ }^{1}$ & $0.33(0.03-2.87)$ & $0.00(0.00)$ & $0.66(0.11-3.94)$ \\
\hline Indoor air ${ }^{2}$ & $0.00(0.00)$ & $0.50(0.04-5.25)$ & $2.00(0.19-21.03)$ \\
\hline \multicolumn{4}{|c|}{ Aspergillus terreus } \\
\hline Indoor dust & $1.00(-)$ & $1.50(0.25-8.86)$ & $0.00(0.00)$ \\
\hline Outdoor dust & $0.00(0)$ & $0.50(0.04-5.25)$ & $0.00(0.00)$ \\
\hline Indoor air & $0.25(0.03-1.89)$ & $0.25(0.03-1.89)$ & $1.00(-)$ \\
\hline \multicolumn{4}{|c|}{ Aspergillus fumigatus } \\
\hline Indoor dust & $1.00(-)$ & $-(-)$ & $0.50(0.04-5.25)$ \\
\hline Outdoor dust & $0.00(0)$ & $-(-)$ & $0.00(-)$ \\
\hline Indoor air & $2.00(0.37-10.55)$ & $0.66(0.11-3.94)$ & $0.00(-)$ \\
\hline \multicolumn{4}{|l|}{ Alternaria } \\
\hline Indoor dust & $0.14(0.02-0.86)^{*}$ & $0.66(0.11-3.94)$ & $1.00(-)$ \\
\hline Outdoor dust & $0.75(0.16-3.33)$ & $0.50(0.04-5.25)$ & $2.00(0.37-10.55)$ \\
\hline Indoor air & $3.00(0.34-25.83)$ & $0.00(0.00)$ & $1.00(-)$ \\
\hline \multicolumn{4}{|l|}{ Cladosporium } \\
\hline Indoor dust & $0.25(0.03-1.89)$ & $0.33(0.03-2.87)$ & $2.00(0.37-10.55)$ \\
\hline Outdoor dust & $-(-)$ & $-(-)$ & $0.33(0.03-2.87)$ \\
\hline Indoor air & $0.75(0.16-3.33)$ & $0.00(0.00)$ & $3.00(0.34-25.83)$ \\
\hline \multicolumn{4}{|l|}{ Penicillium } \\
\hline Indoor dust & $0.66(0.11-3.94)$ & $0.66(0.11-3.94)$ & $1.00(-)$ \\
\hline Outdoor dust & $1.50(0.25-8.86)$ & $2.00(0.37-10.55)$ & $-(-)$ \\
\hline Indoor air & $-(-)$ & $0.66(0.11-3.94)$ & $0.00(0.00)$ \\
\hline
\end{tabular}

OR, Odds ratio; $\mathrm{Cl}$, confidence interval. Note. - , result not shown.

$* P=0.07$ which can be considered as borderline in comparison to the statistical significance level $(p<0.05)$.

${ }^{1} \mathrm{In}-\mathrm{CFU} / 100 \mathrm{~cm}^{2} ;{ }^{2} \mathrm{In}-\mathrm{CFU} / \mathrm{m}^{3}$. 
Table 5. Distribution of atopic patients with asthma, atopic dermatitis, or rhinitis according to Skin Prick Test reactivity and exposure to fungal genera.

\begin{tabular}{|c|c|c|c|c|c|c|c|c|c|c|}
\hline \multicolumn{11}{|c|}{ Sampling places } \\
\hline \multirow[b]{2}{*}{$\begin{array}{l}\text { Case } \\
\text { groups }\end{array}$} & \multirow[b]{2}{*}{$\begin{array}{l}\text { Fungal } \\
\text { type }\end{array}$} & \multicolumn{3}{|c|}{ Indoor dust } & \multicolumn{3}{|c|}{ Outdoor dust } & \multicolumn{3}{|c|}{ Indoor air } \\
\hline & & Mild* & $\begin{array}{l}\text { Moderate to } \\
\text { severe }\end{array}$ & $\begin{array}{c}p- \\
\text { value }^{\#}\end{array}$ & Mild* & $\begin{array}{l}\text { Moderate to } \\
\text { severe }\end{array}$ & $\begin{array}{c}p- \\
\text { value }^{\#}\end{array}$ & Mild* & $\begin{array}{l}\text { Moderate to } \\
\text { severe }{ }^{* *}\end{array}$ & $\begin{array}{c}p- \\
\text { value }^{\#}\end{array}$ \\
\hline & $\mathrm{Asp}^{1}$ & $0(0.0)$ & $3(33.3)$ & 0.23 & $0(0.0)$ & $1(11.1)$ & 1.00 & $1(16.7)$ & $2(22.2)$ & 1.00 \\
\hline & Pen $^{2}$ & $5(62.5)$ & $2(28.6)$ & 0.31 & $4(50)$ & $1(14.3)$ & 0.28 & $6(75.0)$ & 1 (14.3) & 0.04 \\
\hline & $\mathrm{Alt}^{3}$ & $3(75)$ & $10(90.9)$ & 0.47 & $1(25)$ & $5(45.5)$ & 0.60 & $3(75.0)$ & $6(54.5)$ & 0.48 \\
\hline \multirow[t]{3}{*}{$\begin{array}{l}\text { Atopic } \\
\text { dermatitis }\end{array}$} & Asp $^{1}$ & $0(0.0)$ & $0(0.0)$ & - & $0(0.0)$ & $0(0.0)$ & - & $1(10.0)$ & $3(60.0)$ & 0.07 \\
\hline & Pen $^{2}$ & $5(45.5)$ & $3(75)$ & 0.56 & $3(27.3)$ & $2(50)$ & 0.56 & $9(81.8)$ & $3(75.0)$ & 1.00 \\
\hline & $\mathrm{Alt}^{3}$ & 7 (77.8) & $4(66.7)$ & 1.00 & $6(66.7)$ & $4(66.7)$ & - & $9(100)$ & $6(100)$ & - \\
\hline \multirow{3}{*}{$\begin{array}{l}\text { Allergic } \\
\text { rhinitis }\end{array}$} & Asp $^{1}$ & $0(0.0)$ & $2(20)$ & 0.52 & $0(0.0)$ & $0(0.0)$ & - & $0(0.0)$ & $2(20.0)$ & 0.52 \\
\hline & $\mathrm{Pen}^{2}$ & $1(50)$ & $2(15.4)$ & 0.37 & $0(0.0)$ & $2(15.4)$ & 1.00 & $0(0.0)$ & $6(46.2)$ & 0.48 \\
\hline & $\mathrm{Alt}^{3}$ & $3(60)$ & $5(50)$ & 1.00 & $2(40)$ & $4(40)$ & 1.00 & $4(80.0)$ & $8(80.0)$ & 1.00 \\
\hline
\end{tabular}

${ }^{1}$ Aspergillus; ${ }^{2}$ Penicillium; ${ }^{3}$ Alternar.

*Number (\%) of patients exposed to fungal type with mild SPT reactivity.

**Number (\%) of patients exposed to fungal type with moderate to severe SPT reactivity.

${ }^{\#} P$-values are based on Fisher exact test.

Note. -, result not shown.

Distribution of atopic patients according to their SPT reactivity and exposure to indoor and outdoor fungi are presented in Table 5. Correlation analysis showed a significant relation between indoor air Penicillium levels in houses of asthmatic patients and SPT reactivity $(p=0.04)$. Also, correlation between presence of Aspergillus fumigatus in indoor air and SPT reactivity was borderline $(p=0.07)$. However, no significant relation was found between both indoor or outdoor dust fungi and SPT reactivity in any of the three atopic categories. Correlation analysis between presence of fungi and SPT reactivity in atopic patients as total (irrespective of atopic type) was also performed; the results showed a significant relationship between Aspergillus fumigatus present in indoor dust and SPT reactivity $(p=0.05)$. No other fungi in indoor air or outdoor dust were significantly correlated to SPT reactivity.

\section{Discussion}

The recent increase in respiratory and dermal allergy diseases has evoked concerns in public as well as scientific communities worldwide. Associations between air- and dustborne fungi and development of allergy diseases have been reported in several studies (Downs et al., 2001; Gent et al., 2002; Stark et al., 2003, 2005; Rosenbaum et al., 2010; Tischer et al., 2011).

Out of 18 fungal genera found in the present matched case-control study, a similar fungal diversity was observed among the three sampled types (i.e. indoor dust, outdoor dust and indoor air) in all the sampled houses $(N=90)$. However, some differences were also observed; the most prevalent fungi were Yeast, Aspergillus, Alternaria and Penicillium. Other fungal genera, e.g., Rhizopus, Mocur, Fuzarium, etc. were of lower prevalence. Previous reports from different countries have also demonstrated that Alternaria, Cladosporium, Penicillium and Aspergillus were the most prevalent fungi in indoor and outdoor air. For example, Sun et al. reported that the most frequent fungal genera in 
different residential houses of Tekirdag city (Turkey) were Penicillium, Cladosporium and Alternaria (Sen \& Asan, 2009). Also, the most commonly encountered fungi in homes of atopic children in Delhi, India, were Aspergillus, Cladosporium, Alternaria and Penicillium (Sharma et al., 2012). Moreover, recent studies of O'Connor et al. (2004), Crawford et al. (2015) and Shelton et al. (2002) in United States' homes revealed that predominant airborne fungi were Cladosporium, Penicillium, Aspergillus, Alternaria.

Among different species of the Aspergillus genus found in our study, six species with the higher prevalence were named while other species were referred to simply as Aspergillus sp. Of note, A. niger and A. flavus constituted the majority among all the found species of this genus. This is in agreement with the observation of Awad et al. that found Aspergillus flavus and Aspergillus niger as the dominant Aspergillus species in urban and rural homes in Egypt (Awad et al., 2013). Similarly, Durugbo et al. reported that $A$. niger was one of the most frequently occurring fungi in air samples from different sites of Redemption City, Nigeria (Durugbo et al., 2013). All in all, our data confirm the ubiquitous nature of the aforementioned genera of fungi in outdoor and indoor samples.

Interestingly, increased indoor dust-borne Alternaria levels were significantly associated with lower prevalence of asthma. This inverse association has also been reported for another fungus where the odds of wheeze were reduced with elevated indoor dustborne yeast levels (Behbod et al., 2013). In contrast, elevated indoor air-borne levels of fungal genera known to be associated with reduced asthma control (Tischer et al., 2011) (i.e. Aspergillus fumigatus and Alternaria), were also risk factors for asthma development in our study. Increased outdoor dust-borne Penicillium was a predictor of atopic dermatitis. Moreover, higher levels of indoor air-borne Aspergillus flavus and Cladosporium, outdoor dust-borne Alternaria and indoor dust-borne Cladosporium were suggestive risk factors for allergic rhinitis. These findings support the hypothesis that fungal exposure can affect the development of allergic diseases (Denning et al., 2006).

There are some studies that reported associations between total fungal levels or measures of total fungi (e.g., dampness, mold, odor, etc.) and allergic diseases (Nafstad et al., 1998; Emenius et al., 2004; Pekkanen et al., 2007). These studies suffer from lack of measures of specific generalevel fungal concentration levels and hence cannot differentiate allergy-inducing fungal types from those with potentially protective activity. In contrast to the above studies, our study focused on individual fungal genera with objective measures i.e. CFU $/ \mathrm{m}^{3}$ or $\mathrm{CFU} / 100 \mathrm{~cm}^{2}$.

To explain why indoor dust-borne Alternaria showed an inverse association with asthma, it should be noted that environmental exposures may have contrasting effects on allergic or asthmatic responses, depending on the compartment exposed, the fungal load encountered, and duration of exposure or susceptibility of the subject (Behbod et al., 2015). Exposures to dustborne Alternaria are not exception. Indoor dust-borne Alternaria may have been ingested as well as inhaled by the subjects. Immune responses in the gastrointestinal system play important role in the development of immune tolerance (Noverr \& Huffnagle, 2004). Therefore, patients with asthma in our study may have developed immune responses to the dust-borne Alternaria following ingestion of high load of this fungus in the dust. Since air-borne Alternaria was associated with increased asthma occurrence, it is possible that it may reflect a compartmentspecific irritant activity rather than an allergic response in the airways; Correlation analysis between SPT and Alternaria in asthmatic patients with insignificant results (Table 5) also tends to support this explanation. In addition, as there are many species within Alternaria genus, diversity in allergenic components of these fungi may differently stimulate innate responses 
(Kaisho \& Akira, 2006). Taken this into account, it is also possible that air-borne and dust-borne Alternaria species differed structurally or functionally in our study and therefore they may have inserted different immunological effects. Future molecular evidences may discover specific components of fungal stimulants that lead to opposing effects on allergic disease development.

Skin testing is an important diagnostic means for allergy and the wheal and flare reactions to a fungal extract tested is also a measure of the immunological mediation of the reaction (Yunginger, 1991). Hence, positive SPT to at least one of the extracts of three distinct fungal species (Aspergillus fumigatus, Penicillium nonatume and Alternaria alternate) was a requirement for all the atopic patients to enter our study. However, correlation analysis between SPT reactivity (mild or moderate-severe) and fungal exposure (separately or in total) did not generally reveal significant relationships. At first glance, this dataset favors not to confirm the immunological basis for the observed associations between fungal exposure and allergy diseases. However, the lack of association between fungal exposure and sensitization test could possibly arise from the number of allergens tested, batch-to-batch variations in the properties of allergen extracts, etc.

\section{Conclusion}

Our study results demonstrated that while outdoor dust-borne Penicillium, indoor air-borne Aspergillus flavus and Cladosporium, outdoor dust-borne Alternaria and indoor dust-borne Cladosporium were suggestive risk factors for allergic diseases, indoor dust-borne Alternaria had a significant inverse association with asthma prevalence. These findings support the notion that fungal exposures may play role in either increasing or decreasing the development of allergic diseases. Further studies by using molecular techniques are highly recommended for a better evaluation of the allergenic roles of all living and non-living allergenic fungal moieties. Beside this fungal concentration levels evaluation at the species rather than the genera level can improve the specificity of the results.

\section{Acknowledgments}

This work was conducted as a student master thesis project in environmental health engineering. The authors are grateful to the staff of environmental health engineering and medical mycology laboratories for their support in this study.

\section{Declaration of interest}

The authors declare no competing interests.

\section{Funding}

This work was supported by Bushehr University of Medical Sciences [grant number 91100].

\section{References}

Adhikari A, Sen MM, Gupta-Bhattacharya S, Chanda S. (2004). Volumetric assessment of airborne fungi in two sections of a rural indoor dairy cattle shed. Environ Int, 29, 1071-78. 
Akhzari D, Pessarakli M, Shayesteh K, Bashir Gonbad M. (2014). Effect of Source Areas anthropogenic activities on dust storm occurrences in the Western Parts of Iran. Err, 2, 124-32.

Al-Barakah F, Radwan S, Modaihsh A. (2014). Seasonal and spatial variation of microbial contents in falling dust in Riyadh city, Saudi Arabia. Int J Curr Microbiol App Sci, 3, 647-56.

Allergic Rhinitis and its Impact on Asthma (ARIA). (2013). Available at: http://www.whiar.org/ Documents\&Resources.php\#1. Accessed May 08, 2017.

Amanollahi J, Kaboodvandpour S, Qhavami S, Mohammadi B. (2015). Effect of the temperature variation between Mediterranean Sea and Syrian deserts on the dust storm occurrence in the western half of Iran. Atmos Res, 154, 116-25.

Assarehzadegan MA, Shakurnia A, Amini A. (2013). The most common aeroallergens in a tropical region in Southwestern Iran. World Allergy Organ J, 6, 7.

Awad AHA, Gibbs SG, Tarwater PM, Green CF. (2013). Coarse and fine culturable fungal air concentrations in urban and rural homes in Egypt. Int J Environ Res Public Health, 10, 936-49.

Behbod B, Sordillo J, Hoffman E, et al. (2013). Wheeze in infancy: protection associated with yeasts in house dust contrasts with increased risk associated with yeasts in indoor air and other fungal taxa. Allergy, 68, 1410-18.

Behbod B, Sordillo J, Hoffman E, et al. (2015). Asthma and allergy development: contrasting influences of yeasts and other fungal exposures. Clin Exp Allergy, 45, 154-63.

Bush RK, Portnoy JM. (2001). The role and abatement of fungal allergens in allergic diseases. J Allergy Clin Immunol, 107, S430-S40.

Bush RK, Portnoy JM, Saxon A, et al. (2006). The medical effects of mold exposure. J Allergy Clin Immunol, 117, 326-33.

Chadeganipour M, Shadzi SH, Nilipour SH, Ahmadi GH. (2010). Airborne fungi in Isfahan and evaluation of allergenic responses of their extracts in animal model. Jundishapur J Microbiol, 3, 155-60.

Chao HJ, Chan CC, Rao CY, et al. (2012). The effects of transported Asian dust on the composition and concentration of ambient fungi in Taiwan. Int J Biometeorol, 56, 211-19.

Crameri R, Garbani M, Rhyner C, Huitema C. (2014). Fungi: the neglected allergenic sources. Allergy, 69, 176-85.

Crawford JA, Rosenbaum PF, Anagnost SE, et al. (2015). Indicators of airborne fungal concentrations in urban homes: understanding the conditions that affect indoor fungal exposures. Sci Total Environ, 517, 113-24.

Denning D, O'driscoll B, Hogaboam C, et al. (2006). The link between fungi and severe asthma: a summary of the evidence. Eur Resp J, 27, 615-26.

Downs SH, Mitakakis TZ, Marks GB, et al. (2001). Clinical importance of Alternaria exposure in children. Am J Respir Crit Care Med, 164, 455-59.

Dreborg S. (1989). The skin prick test in the diagnosis of atopic allergy. J Am Acad Dermatol, 21, $820-21$.

Durugbo E, Kajero A, Omoregie E, Oyejide N. (2013). A survey of outdoor and indoor airborne fungal spora in the Redemption City, Ogun State, south-western Nigeria. Aerobiologia, 29, 201-16.

Eichenfield LF, Tom WL, Chamlin SL, et al. (2014). Guidelines of care for the management of atopic dermatitis: section 1. Diagnosis and assessment of atopic dermatitis. J Am Acad Dermatol, $70,338-51$.

Emenius G, Svartengren M, Korsgaard J, et al. (2004). Indoor exposures and recurrent wheezing in infants: a study in the BAMSE cohort. Acta Paediatr, 93, 899-905.

Farrokhi S, Gheybi MK, Movahhed A, et al. (2014). Prevalence and risk factors of asthma and allergic diseases in primary schoolchildren living in Bushehr, Iran: phase I, III ISAAC protocol. Iran J Allergy Asthma Immunol, 13, 348.

Gent JF, Ren P, Belanger K, et al. (2002). Levels of household mold associated with respiratory symptoms in the first year of life in a cohort at risk for asthma. Environ Health Perspect, 110, A781.

Gheybi MK, Movahed A, Dehdari R, et al. (2014). Dusty air pollution is associated with an increased risk of allergic diseases in Southwestern Part of Iran. Iran J Allergy Asthma Immunol, 13, 404. 
Hong SJ, Ahn KM, Lee SY, Kim KE. (2008). The prevalences of asthma and allergic diseases in Korean children. Korean J Pediatr, 51, 343-50.

Kaisho T, Akira S. (2006). Toll-like receptor function and signaling. J Allergy Clin Immunol Pract, 117, 979-87; quiz 88.

Kellogg CA, Griffin DW. (2006). Aerobiology and the global transport of desert dust. Trends Ecol Evol, 21, 638-44.

Khora SS. (2016). Seafood-associated shellfish allergy: A comprehensive review. Immunol Invest, 45, 504-30.

Mosca T, Menezes MC, Silva AV, et al. (2015). Chemotactic and phagocytic activity of blood neutrophils in allergic asthma. Immunol Invest, 44, 509-20.

Nafstad P, Oie L, Mehl R, et al. (1998). Residential dampness problems and symptoms and signs of bronchial obstruction in young Norwegian children. Am J Respir Crit Care Med, 157, 410-14.

Noverr MC, Huffnagle GB. (2004). Does the microbiota regulate immune responses outside the gut? Trends Microbiol, 12, 562-68.

O'Connor GT, Walter M, Mitchell H, et al. (2004). Airborne fungi in the homes of children with asthma in low-income urban communities: the Inner-City Asthma Study. J Allergy Clin Immunol, 114, 599-606.

Pawankar R, Canonica GW, Holgate ST, Lockey RF. (2011). editors. The WAO white book on allergy. World Allergy Organization. pp. 1-216. http://www.worldallergy.org/UserFiles/file/ WAO-White-Book-on-Allergy.pdf.

Pekkanen J, Hyvarinen A, Haverinen-Shaughnessy U, et al. (2007). Moisture damage and childhood asthma: a population-based incident case-control study. Eur Respir J, 29, 509-15.

Rosenbaum PF, Crawford JA, Anagnost SE, et al. (2010). Indoor airborne fungi and wheeze in the first year of life among a cohort of infants at risk for asthma. J Expo Sci Environ Epidemiol, 20, 503-15.

Sánchez-Lerma B, Morales-Chirivella F, Peñuelas I, et al. (2009). High prevalence of asthma and allergic diseases in children aged 6 and 7 years from the Canary Islands: the International Study of Asthma and Allergies in Childhood. J Investig Allergol Clin Immunol, 19, 383-90.

Sen B, Asan A. (2009). Fungal flora in indoor and outdoor air of different residential houses in Tekirdag City (Turkey): seasonal distribution and relationship with climatic factors. Environ Monit Assess, 151, 209-19.

Sharma R, Deval R, Priyadarshi V, et al. (2011). Indoor fungal concentration in the homes of allergic/asthmatic children in Delhi. India Int Forum Allergy Rhinol, 2, 21.

Sharma R, Gaur SN, Singh VP, Singh AB. (2012). Association between indoor fungi in Delhi homes and sensitization in children with respiratory allergy. Med Mycol, 50, 281-90.

Shelton BG, Kirkland KH, Flanders WD, Morris GK. (2002). Profiles of airborne fungi in buildings and outdoor environments in the United States. Appl Environ Microbiol, 68, 1743-53.

Soleimani Z, Goudarzi G, Naddafi K, et al. (2013). Determination of culturable indoor airborne fungi during normal and dust event days in Ahvaz, Iran. Aerobiologia, 29, 279-90.

Stark PC, Burge HA, Ryan LM, et al. (2003). Fungal levels in the home and lower respiratory tract illnesses in the first year of life. Am J Respir Crit Care Med, 168, 232-37.

Stark PC, Celedón JC, Chew GL, et al. (2005). Fungal levels in the home and allergic rhinitis by 5 years of age. Environ Health Perspect, 113, 1405-09.

Tang JW. (2009). The effect of environmental parameters on the survival of airborne infectious agents. J R Soc Interface, 6, S737-S746.

The Global Initiative for Asthma (GINA). (2017). 2017 GINA Report, Global Strategy for Asthma Management and Prevention. Available at: http:/ginasthma.org/2017-gina-report-global-strat egy-for-asthma-management-and-prevention/. Accessed May 08, 2017.

Tischer C, Chen CM, Heinrich J. (2011). Association between domestic mould and mould components, and asthma and allergy in children: a systematic review. Eur Resp J, 38, 812-24.

Yunginger J. (1991). Standardization of allergenic extracts. Ann Allergy, 66, 107. 